\title{
FRONTERAS MARÍTIMAS EN EL MEDITERRÁNEO BAJOMEDIEVAL. INCIDENCIAS, CONFLICTO Y NEGOCIO ENTRE LA CORONA DE ARAGÓN Y TÚNEZ A PARTIR DE UN EPISODIO DE 1413
}

\author{
MARITIME FRONTIERS IN THE LATE MEDIEVAL MEDITERRANEAN. \\ INCIDENTS, CONFLICT AND BUSINESS BETWEEN THE CROWN \\ OF ARAGON AND TUNIS BASED ON AN OCCURRENCE OF 1413
}

\section{Carlos CRESPO AMAT* \\ J. Leonardo SOLER MILLA ** \\ Universidad de Alicante}

Resumen: En el presente artículo se aborda una de las manifestaciones de la frontera marítima de la Corona de Aragón en el Mediterráneo bajomedieval a través de una incidencia naval de 1413 que demuestra la complejidad de las realidades socio-económicas de naves y mercaderes en las que la violencia, el negocio, la pluriconfensionalidad, la ambigüedad jurídica, la solidaridad, entre tantos otros aspectos, formaban parte de un todo.

Palabras clave: Frontera marítima, Mediterráneo, Corona de Aragón, Magreb, cristianos, musulmanes, judíos, violencia, conflicto, negocio, siglo XV.

\begin{abstract}
This article will reveal one of several manifestations of the maritime frontier of the Crown of Aragon in the Late Medieval Mediterranean based on a naval occurrence of 1413. This incident demonstrates the complexity of the socio-economic realities in which violence, business, the varieties of faith, the legal ambiguity, solidarity, among many others, were part of a whole.
\end{abstract}

Key words: maritime frontiers, Mediterranean, Crown of Aragón, Maghreb, Christians, Muslims, Jews, violence, conflict, business, $15^{\text {th }}$ Century.

\footnotetext{
Investigador predoctoral del programa nacional de ayudas para la Formación de Profesorado Universitario del Ministerio de Educación, Cultura y Deporte (FPU15/00157), Departamento de Historia Medieval, Historia Moderna y Ciencias y Técnicas Historiográficas de la Universidad de Alicante. Correo electrónico.: carlos.crespo@ua.es.

** Profesor Ayudante Doctor en Historia Medieval, Departamento de Historia Medieval, Historia Moderna y Ciencias y Técnicas Historiográficas de la Universidad de Alicante. Correo electrónico: leonardo. soler@ua.es.
} 


\section{Introducción ${ }^{1}$}

El estudio de la frontera - en singular, sin más concreción que la que sugiere su significante - no es, en absoluto, un campo de investigación reciente. Incluso prescindiendo de la vetusta inquietud política hacia ella, el interés por la frontera en retrospectiva ha ocupado una posición central en la producción historiográfica europea desde, al menos, el segundo cuarto del siglo XX. Sin embargo, la temática es fecunda y se mantiene en permanente estado de actualización, toda vez que siguen sorprendiendo los resultados de estudios diversos en sus objetivos y planteamientos y las nuevas reflexiones en torno a la definición y las particularidades de la frontera y los espacios fronterizos surgidos de equipos y trabajos de investigación que han enriquecido el análisis al abrir nuevas vías de aproximación y descubrir problemáticas hasta entonces inexploradas. Es así como la proliferación de estudios en las últimas décadas ha alcanzado tan alto grado que la complejidad que encierra el fenómeno, en tanto que sujeto histórico, ha derivado en un estado en el que es posible identificar tantas fronteras como vías de aproximación existen a las múltiples manifestaciones de las mismas. ${ }^{2}$

En el fondo, sin embargo, la variabilidad de la frontera puede reducirse a sus dos expresiones naturales más elementales: la terrestre y la marítima. Y aunque - para el caso que aquí interesa - a lo largo del periodo medieval hispánico, y específicamente durante la Baja Edad Media catalano-aragonesa, la terrestre fue la frontera por definición, reconocible y aun tópica en la realidad peninsular cristiana por su linde inconfundible con Granada, la otra expresión de la frontera, la frontera marítima, fue siempre otro espacio de contacto y de proyección política, socioeconómica y religioso-cultural tan dinámico como aquélla; si no más, por cuanto su existencia no estaba únicamente -e, incluso, fundamentalmente - condicionada a la pervivencia andalusí representada por el reino nazarí, sino también a la hegemonía musulmana en el sector occidental de la dār al-Islām o, lo que es lo mismo, Berbería.

No obstante, la frontera marítima sigue adoleciendo de un corpus teórico que la defina y la singularice frente a la frontera tradicional. Por ello su inci-

1 Este artículo se inserta en el Proyecto de Investigación I+D: «Comercio internacional e integración económica en la Europa mediterránea y atlántica: los puertos del reino de Valencia (siglos XIII-XV)» (GV/2018/016), de la Conselleria de Educación, Cultura y Deporte, Generalitat Valenciana cuyo IP es Juan Leonardo Soler Milla.

2 La última actualización, por no alargar la cita, en Salicrú, 2018. 
dencia en la Baja Edad Media o, mejor dicho, el rol de la economía en las sociedades mediterráneas de los siglos XIV y XV en las que se desarrolló este fenómeno $-\mathrm{y}$, por consiguiente, las actividades socioeconómicas típicas y cotidianas de los espacios de frontera-, debe situarse en el plano de las diferentes visiones de frontera y de espacios fronterizos aportadas por la historiografía medievalista. Los estudios iniciales, tanto para el área castellana y portuguesa como para la Corona de Aragón, mostraron un interés por la frontera marítima no en tanto que sujeto histórico, sino como expresión, por otra vía - la marítima -, de los avances de la conquista militar frente al Islam peninsular, destacando la importancia de la flota castellana y catalano-aragonesa en la toma de las principales ciudades costeras o fluviales. ${ }^{3}$

El reclamo de una especificidad de la frontera marítima y origen de lo que hasta hoy se ha consolidado como una línea de investigación especializada en los estudios fronterizos es, en buena medida, mérito de J. E. López de Coca (1978; 1997; y 1999), quien ha tipificado los diferentes niveles de definición de la frontera marítima en base a las improvisadas políticas de defensa de la costa, la incidencia económica del corso y la piratería y las repercusiones de la formación de redes de cautiverio. ${ }^{4}$

Las medidas adoptadas por los poderes políticos peninsulares a fin de proteger el litoral, con el establecimiento o la implementación, a lo largo sobre todo del sigo $\mathrm{XV}$, de nuevos medios arquitectónicos y humanos más o menos efectivos han sido estudiadas para toda la fachada mediterránea, desde el Rosellón hasta las costas de Málaga, por diversos grupos de investigación, ${ }^{5}$ aun cuando las fuentes cristianas no permiten siempre dilucidar la facticidad de las disposiciones que contienen y los textos medievales árabes (Alarcón y García de Linares, 1940; Zomeño, 2001; Salicrú, 2009) son escasos en número y en información sobre la frontera del mar (Arié, 1990: 265; López de Coca, 1997:

3 Una síntesis de esta concepción historiográfica de la frontera marítima, aunque centrada en el área castellana y en el papel del poder naval en la expansión política y militar, puede verse en Flores, 2000 También del mismo autor resulta interesante para una conceptualización histórica: Flores, 1998. Vid. $u$ na actualización historiográfica en el dossier coordinado por E. Aznar Vallejo y R. J. González Zalacain, «Europa y el Mar. Las nuevas fronteras» del número 18 (2018) de la revista Vegueta: Anuario de la Facultad de Geografía e Historia de la ULPGC.

4 Si bien centrándose en el periodo nazarí y el momento final de la conquista de Granada y en la costa almeriense y malagueña (López de Coca, 1978; 1997).

5 La bibliografía sobre la defensa del litoral y los sistemas de vigilancia costeros es muy abundante. Los trabajos citados de J. E. López de Coca siguen siendo de referencia obligada. Desde una perspectiva arqueológica, también Gamir, 1960; Temboury; Reyes y Rubio, 1978. Para la Corona de Aragón: Díaz, 1993; M. D. López, 1995. 
395). En el caso catalano-aragonés, y específicamente en el valenciano, los trabajos realizados coinciden en destacar la escasa efectividad de la defensa de la costa debido, por una parte, a la inoperatividad de la red de torres vigías y del sistema de avisos ante la incapacidad de las haciendas locales de hacerse responsables de su mantenimiento y, por otra, al carácter accidentado del litoral, que forma extraordinarios refugios naturales donde piratas y corsarios podían aguardar el momento oportuno para llevar a cabo una terraçania o resguardarse en caso de ser perseguidos (Ferrer, 1988: 169-170); López de Coca, 1997).

En efecto, el corso y la piratería son, por la conmoción política y social que generaban, las manifestaciones en negativo que más reflejo documental han dejado y por ello las que, junto al comercio ${ }^{6}$ y el resto de intercambios transfronterizos, más interés han suscitado en la investigación medieval. Para el ámbito de la Corona de Aragón existen numerosos y bien documentados trabajos que, desde perspectivas y observatorios diferentes, han identificado y explicado episodios de piratería y corsarismo, especialmente del siglo XV. Se trata, en algunos casos, de obras ya clásicas por la resonancia historiográfica que han tenido $\mathrm{y}$, en otros, de aportaciones más recientes a la temática realizadas con nuevos enfoques y una exhaustiva heurística de base archivística. Suficientemente conocidos son los trabajos de Maria Teresa Ferrer i Mallol (1987), José Hinojosa (1975; 1978; 1985; 1987; 1988; 1989; 1990), Anna Unali (2007), Andrés Díaz Borrás (1986; 1988a; 1988b; 1990; 1993) y Roser Salicrú (1998; 1999a; 1999b; 2000; 2002; 2007; 2018), entre otros.

La aproximación a las repercusiones de la formación de redes de cautiverio, en último lugar, se ha desarrollado en la línea de lo que J. E. López de Coca ha calificado de neurosis granadina (1982: 651) entre las poblaciones cristianas costeras, así como en las estrategias, instituciones y actitudes diseñadas para el rescate y redención de cautivos (Díaz, 1986: 337-353; Ferrer, 1988; López de Coca, 1989; López de Coca, 1997: 400-411 y 406-407; Cabe-

6 La ampliación del cuerpo de reflexiones hacia el campo socioeconómico ha permitido plantear nuevas propuestas sobre el comercio de la corona de Aragón con Berbería y el reino nazarí de Granada; la logística de las asociaciones/grupos de piratas y corsarios organizados para este fin; la percepción política de los asuntos que engloban la frontera marítima: negociación política, redes de intereses y negocio de diferentes actores sociales y regulación de los lugares de intercambio/robo/redistribución de mercancías, la incidencia pirática de naves procedentes de los vecinos reinos de Granada y Castilla en el entramado económico catalanoaragonés; la merceología y el tráfico de esclavos que comportan; etc. 
zuelo: 1997-1998: 43-58). No obstante, esta vía historiográfica parece más una ampliación del marco de la investigación hacia el medio marítimo respecto al mismo fenómeno documentado en la frontera terrestre que una orientación específica dentro del estudio de la frontera marítima.

A pesar de la plétora historiográfica descrita, todavía hoy la frontera peninsular de los siglos bajomedievales no se ha desprendido enteramente de su reminiscencia a la conquista y el avance militar al abrigo de un programa ideológico-religioso, y por ello continúa a veces remitiendo a la frontera entre Castilla y Granada; una frontera, por lo tanto, eminentemente terrestre. Pero aun cuando el fenómeno se hace extensivo al resto de formaciones políticas peninsulares, la frontera se define por oposición al reducto islámico de alAndalus en la Península y consiguientemente, de nuevo, por su manifestación terrestre. En el ámbito de la Corona de Aragón, en efecto, los estudios de los últimos treinta o treinta y cinco años han reclamado el carácter fronterizo del mediodía valenciano, esto es de la gobernación de Orihuela, por la intensidad con la que valencianos y granadinos traspasaban los límites con la finalidad normalmente de saquear y obtener botín. Solo algún estudio puntual ha llamado la atención sobre la frontera marítima valenciano-granadina (Cabezuelo y Soler, 2006; Barrio, 2011-2013). Parece, en consecuencia, que la idea, harto frecuente en el medievalismo peninsular, de una frontera con el Islam se asocia, tanto por tierra como por mar, a la frontera con Granada, eludiendo así un mar Mediterráneo que, sobre todo en el reino de Valencia - por su ubicación geográfica-, no sólo era frontera con el sultanato nazarí sino, de forma mucha más amplia, con el Islam occidental, y concretamente con las tierras de Berbería.

El giro de la investigación hacia esta última concepción de la frontera marítima ha sido, en gran medida, resultado de los estudios realizados en el marco del proyecto de investigación sobre «El Mediterráneo medieval desde el observatorio de la Corona de Aragón. Conflictividad e intercambios económicos» dirigido desde la Institució Milà i Fontanals del Consejo Superior de Investigaciones Científicas por la doctora M. T. Ferrer i Mallol, con una publicación monográfica como hito fundamental en el análisis del tema (Ferrer, 1987) y una rigurosa reflexión elaborada por R. Salicrú i Lluch en torno a sus características, significado y realidades, que se plantea como un sugestivo punto de partida para los estudios, todavía exiguos, de frontera marítima (Salicrú, 2000). 
En su análisis de la frontera marítima, la doctora Salicrú expone aquellas características que distinguen esta manifestación fronteriza, por oposición a la frontera terrestre, y la define como una frontera humana y a la vez natural $-\mathrm{y}$ per se arriesgada-, desprovista de concreción espacial de lo político, omnipresente, ubicua, independiente de las fronteras terrestres y, por extensión, condicionada a las iniciativas individuales

\section{Salir mercantilmente y llegar en modo bandido: negocio, astucia y buena guerra en la costa tunecina}

Los años finales del siglo XIV e iniciales del XV representan un periodo convulso de la historia de la Corona de Aragón. Durante su reinado, Pedro el Ceremonioso trató insistentemente de mediatizar el gobierno de Sicilia, consiguiendo finalmente coronar a su nieto - e hijo primogénito del futuro rey Martín el Humano - en el trono siciliano, si bien de forma perecedera: pues, aunque Martín el Joven reinó en solitario la isla desde 1402 - cuando, tras el fallecimiento de su esposa, rechazó la paz de Catania de 1372 que convertía al rey de Trinacria en feudatario y tributario de Juana, reina de Nápoles y, en virtud del tratado, también de Sicilia-, su muerte siete años más tarde puso fin a la rama sículo-aragonesa. Y aunque el rey Martín el Humano se coronó tras esta situación rey de Sicilia, su muerte prematura dejó de nuevo la isla en un vacío de poder sólo atemperado por la actuación de su esposa, Blanca de Navarra, que asumió la vicaría del reino hasta que la decisión adoptada en el compromiso de Caspe de 1412 puso fin al interregno en los territorios de la corona aragonesa y situó a todos ellos bajo el reinado de Fernando I (Claramunt, 2002-2003; Borguese, 2013: 344-348; Belenguer, 2015).

La comunidad hebrea fue la gran perjudicada de la inestabilidad que imperó durante ese tiempo, máxime tras los asaltos a las juderías en 1391, cuando las tensiones entre cristianos y judíos se enardecieron. En un contexto así, la guerra, la piratería o la mala fortuna podía ser consustancial a las agresiones, a los asaltos y al cautiverio de judíos, como también de musulmanes, especialmente cuando estas minorías procedían del reino de Granada o de la costa norteafricana (Hinojosa, 2006-2008: 23). En el caso de la comunidad hebrea, además, el riesgo de sufrir un ataque de manos de grupos cristianos catalano-aragoneses se había incrementado desde que, tras los 
mencionados asaltos - y pese a los intentos de la Monarquía por normalizar las relaciones sociales con los judíos, al amparo de una política regia de protección-, el antisemitismo arraigó en amplios sectores de la sociedad (Hinojosa, 2008: 105).

Especialmente el comercio con las costas norteafricanas desencadenaba riesgos y era origen de problemas recurrentes debido a la confluencia de embarcaciones en sus puertos con fines mercantiles. La ruta de Berbería, que unía los puertos del Levante peninsular con los de Ceuta, Orán, Argel, Annaba, Bugía y Túnez, era recorrida por un heterogéneo grupo de mercaderes en busca de oro, esclavos y otras mercancías (Unali, 2007: 160-161), así como de mercados en los que redistribuir ciertos productos agropecuarios y recursos naturales o donde contratar servicios a bajo coste. La interculturalidad, solidaridad y violencia entre cristianos, musulmanes y judíos que como consecuencia se generaba en estos puntos de encuentro marítimos eran una consecuencia de los contactos transfronterizos y convergían con frecuencia en el vínculo más connivente entre ellos: el comercio (Salicrú, 2002).

Por ello la denuncia interpuesta en la corte de la bailía general del reino de Valencia por un judío siciliano a finales de 1413 resulta útil para comprobar cómo, a pesar de su activo rol como dinamizador de una variada gama de contactos, la práctica del comercio podía ocasionalmente activar otros procesos que rebasaban los intereses mercantiles. Tal es el caso sufrido por Abrahim Genim ese año durante el desarrollo de su empresa mercantil marítima en la costa tunecina. ${ }^{7}$

A mediados de mayo de 1413 este judío de origen palermitano o catanés había firmado un contrato de fletamento con otro siciliano para desplazarse modo mercatorio desde Palermo hasta la ciudad de Túnez, puerto de entrada a Ifriqiya $-\mathrm{y}$, junto al de Orán, el más dinámico de la costa norteafricana - , y llevar a cabo sus negocios mercantiles (Valérian, 2006; Valérian, 2016). Junto al fletador, el patrón - Guglielmo di Gordato, de Trapani- y el escribano, a bordo del San Giuliano, que así es como se llamaba la barcha grossa contratada, iban varios mercaderes de Sicilia que habían adquirido derechos de porte para llevar sus mercancías al puerto de destino. Brachono Givi, Shabtai Sabeti o Abraham di Hue son los nombres de algunos de ellos, evidenciando una clara filiación hebrea.

7 El pleito se encuentra en Archivo del Reino de Valencia (ARV), Bailia, n. 1429, $3^{\mathrm{a}}$ mano, f. 9r-v; $4^{\mathrm{a}}$ mano, f. 32r-v; $5^{\mathrm{a}}$ mano, f. 5r-29c; $6^{\mathrm{a}}$ mano, ff. 22r-v y 38r-48v; $7^{\mathrm{a}}$ mano, ff. 1r-17v y 20r-30r. 
En el San Giuliano embarcaron, en efecto, muchos mercaderes judíos cuya procedencia suponía en el contexto político mediterráneo de 1413 que Genim y varios de los hombres de la nave trapanesa eran vasallos del rey de Aragón, si bien no todos eran originarios de Sicilia: los había de Palermo, Trapani, Catania y Mesina; otros eran de Málaga; y algunos mercaderes procedían incluso de Barcelona. Había también varios hombres de negocios de Venecia y de otras partes de Italia, mientras que de los restantes nada se especifica sobre su origen, o tal vez eran cristianos - pues los había, aunque en reducido número.

Tabla 1. Compañía del San Giuliano

\begin{tabular}{|c|c|c|}
\hline Nombre & Oficio & Origen \\
\hline Mehl Ahmad & marinero & Sicilia \\
\hline Bartolomeo Simone Andree & mercader & Palermo \\
\hline Isac Burjí ( $\nLeftarrow$ ) & marinero & Península Ibérica (¿Málaga?) \\
\hline \multicolumn{3}{|l|}{ Diego di Cantitura } \\
\hline Abrahim Genim ( $\bowtie$ ) & mercader & Palermo (¿o Catania?) \\
\hline Antonio della Gente & & Venecia \\
\hline Brachono Givi ( & mercader & Palermo \\
\hline Guglielmo di Gordato & patrón de barco & Trapani \\
\hline Bartolomeo Guglielmi ( $₫$ ) & mercader & Palermo \\
\hline Abraham di Hue ( & marinero & Sicilia \\
\hline Giacomo Giovanni di Jaela & & Génova \\
\hline Brachono Jam ( $\bowtie$ ) & & Palermo \\
\hline Tommaso Leccavela & & Génova \\
\hline Bernat ça Nou & & Barcelona \\
\hline Pappagallo (y sus marineros) & marinero & Sicilia \\
\hline Isac Rabbi ( ) & marinero & Sicilia \\
\hline Judah Rotí ( $\bowtie$ ) & marinero & Península Ibérica (¿Málaga?) \\
\hline Boaz Sabeti ( $\bowtie$ ) & & Palermo \\
\hline Shabtai Sabeti ( $\bowtie$ ) & marinero & Sicilia \\
\hline Abraham ( $\notin$ ) & & Trapani \\
\hline Battista & marinero & \\
\hline
\end{tabular}


La composición del grupo de mercaderes a bordo del San Giuliano es un indicio del éxito del modelo comercial autónomo que eclosiona en Sicilia a finales del siglo XIV y se consolida a comienzos del XV. Efectivamente, en el San Giuliano habían embarcado varios judíos venecianos y de otras ciudades italianas e, incluso, cristianos procedentes de Italia; sin embargo, la participación estos mercaderes es aquí residual y dista mucho de la anterior dependencia de los sicilianos de los medios genoveses y venecianos para llevar a cabo sus empresas marítimas mercantiles. Por su parte, la presencia en la barca de granadinos, tal vez también de castellanos y, sobre todo, de catalanes responde a la situación estratégica de Sicilia para el desarrollo del comercio mediterráneo y, por consiguiente, a los vínculos que durante mucho tiempo mantuvieron los habitantes del litoral ibérico con la isla, donde siempre habían sido bien recibidas sus embarcaciones para realizar travesías marítimas a lo largo de los dos sectores del Mediterráneo, máxime en el caso de los catalanes cuyo interés por el mercado de esclavos norteafricanos era compartido por sicilianos y concentró a no pocos catalanes en Trapani y Catania participando en él (Duran, 2005: 69, 72 y 81).

En las bodegas del San Giuliano habían sido cargadas, en Palermo o en Trapani - única escala del viaje - , varios centenares de mercancías por las que se pagaron los correspondientes derechos de aduana en el puerto tunecino y por las que se solicitaron salvoconducto al sultán de Ifriqiya, que concedió vía libre para el tránsito y comercio a lo largo del territorio tunecino de las mercancías y mercaderes embarcados.

Tabla 2. Mercancías cargadas en el San Giuliano

\begin{tabular}{|l|l|l|l|}
\hline Mercancía & Cantidad & Mercancía & Cantidad \\
\hline algodón en hilo & $\begin{array}{l}3 \text { quintales, } 14 \\
\text { rollos }\end{array}$ & joyas & {$[\cdots]$} \\
\hline alumbre & 16 sacas & orchilla & 3 gerres \\
\hline azafrán & 30 rollos & plomo & 86 quintares \\
\hline azufre & 1 carratell & queso & 66 hilos \\
\hline carbonato de plomo & 3 barriles & tártaro & 1 bota \\
\hline cobre & {$[\cdots]$} & textiles & {$[\cdots]$} \\
\hline confite de azúcar & 1 carretell & trigo & {$[\cdots]$} \\
\hline hilo de oro & 3 caixetes & vino & 3 botas \\
\hline hoja de latón & 80 docenas & yeso & {$[\cdots]$} \\
\hline
\end{tabular}


Tras partir de Sicilia, la barcha de Guglielmo di Gordato estuvo navegando durante algunos días, vía directa a Túnez, hasta llegar el 9 o el 10 de junio de ese mismo año a su lugar de destino, donde coincidió con otra nave que había partido de Valencia el 7 de marzo. Francesc d'Àries, mercader de Valencia, fue el fletador de la nave, llamada Sankt Christophorus y propiedad de Johannes Kohls, natural de Gdansk, en la histórica y hanseática región de la Pomerania.

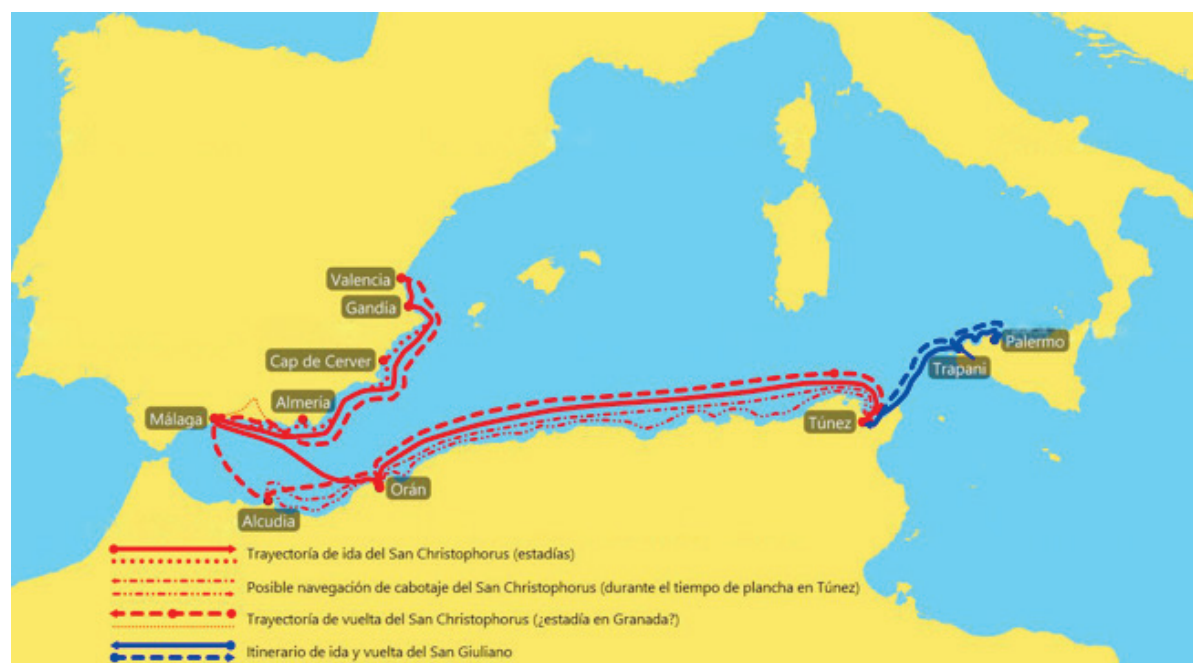

Figura 1. Itinerarios del Sankt Christophorus y del San Giuliano

Aunque de origen germánico, el Sankt Christophorus se definía por su nota de interculturalidad incluso antes de su disposición en el grao de Valencia, pues la compañía de a bordo estaba integrada no sólo por marineros y mercaderes del Sacro Imperio, sino también por flamencos, gascones, portugueses o venecianos, entre otros. En total, veintiocho personas navegaban junto a Johannes Kohls, entre marineros, servidores y dos auxiliares cuya presencia valida la naturaleza móvil, abierta y humana de la frontera marítima: los trujamanes. A bordo iban también dos pilotos de procedencia mallorquina y un escribano de Valencia, además de otros marineros de la Corona de Aragón. Asimismo, en la travesía de vuelta viajaron también varios pasajeros, los más de ellos mercaderes de Barcelona y de Valencia, además de Nicolau Julià, que ejercía de agente mercantil de d'Àries en Túnez y dirigía junto a él la sociedad mercantil encargada de esta empresa. 
Tabla 3. Compañía del Sankt Christophorus (ida y/o vuelta)

\begin{tabular}{|c|c|c|}
\hline Nombre & Oficio & Origen \\
\hline Hendrik van Amerongen & ministril & ¿Condado de Flandes? \\
\hline Francesc d'Àries & mercader & Valencia \\
\hline Pere Baiona & & ¿Barcelona? \\
\hline \multicolumn{3}{|l|}{ Andreu Cardona } \\
\hline Antoni Castell & marinero & \\
\hline Lluís d'Eixarc & mercader & ¿Valencia? \\
\hline Arnau Falcó & tabernero & Valencia \\
\hline Arnau Frasquet & marinero & \\
\hline Bernat Gilabert & mercader & Valencia (¿residente en Fez?) \\
\hline Bernat Godall & & Valencia \\
\hline Jan de la Haye & ministril & ¿Condado de Flandes? \\
\hline Jan Hendrik & ministril & ¿Condado de Flandes? \\
\hline Pietro Jacomart & marinero & Venecia \\
\hline Bernat Gironí & mercader & Barcelona \\
\hline Nicolau Julià & mercader & Valencia \\
\hline Johannes Kohls & patrón de barco & Gdansk (residente en Valencia) \\
\hline Jordi Macip & marinero & Mallorca \\
\hline Leonardo Mannelli & mercader & Florencia (residente en Valencia) \\
\hline Pere Martí & mercader & Valencia \\
\hline Martí Mir & pelaire & \\
\hline Wilhelm Moll & trujamán & Sacro Imperio \\
\hline Bertomeu Nicolau & mercader & Barcelona \\
\hline Joan Pomer & mercader & Peñíscola \\
\hline Bernat Pons & & Valencia \\
\hline Esteve Puig-Ginestós & mercader & Valencia \\
\hline Bartolomeo di Rello & mercader & ¿residente en Túnez? \\
\hline \multicolumn{3}{|l|}{ Pere de Roda } \\
\hline Martí Sanchis & marinero & \\
\hline Henrik & trujamán & Noruega \\
\hline Hermano Julià & fraile (Frailes Menores) & ¿residente en Túnez? \\
\hline
\end{tabular}


El fletamento fue firmado en Valencia el 25 de febrero de 1413 «con la intención y propósito de ir mercantilmente» al puerto de Túnez, haciendo escala en las principales ciudades comerciales de los reinos de Valencia, Castilla, Granada y Tlemecén. ${ }^{8}$ Entre las cláusulas pactadas, d'Àries hizo incluir, en primer lugar, la contingencia de un eventual desplazamiento a las ciudades de Orán o de Alcudia - la actual Ghassassa, cerca de Melilla - , durante los veinticinco días del tiempo de plancha en el puerto de Túnez. En segundo lugar, entre las escalas fijadas para la travesía de vuelta a Valencia propuso dos días útiles y cargables en algún puerto magrebí, previamente comunicado al patrón de la nave, y ocho días con las mismas características en la ciudad de Málaga. En tercer lugar, el contrato incluía una cláusula que permitía prorrogar el tiempo de actividad establecido hasta en diez jornadas, pagaderas al patrón de la embarcación por el duplo del importe diario acordado. Finalmente, se incorporó un acuerdo que el fletante expresaba en los siguientes términos: «inito et conveneo quod omnes proventus sive percatis, quomodocumque et qualitercumque deveniant supra dicte navi sint propria vestri, dicti mercatoris [Francisci Daries]».

En las circunstancias descritas se produjo el avistamiento entre ambas naves, el Sankt Christophorus y el San Giuliano, un encuentro propiciado por la dilación del tiempo de plancha en Túnez. Lo importante de la concurrencia de ambas embarcaciones en el golfo tunecino es que, desde el momento en que Francesc d'Àries tuvo conocimiento de la condición de los bienes embarcados en el San Giuliano, su actitud y la de sus hombres se ajusta al estilo «bandido», - more predonis - : ante la negativa de la tripulación a permitirles el acceso a la embarcación, los predones primero la asaltan con fuerza y violencia y luego con razonamientos capciosos intentan convencer a los asaltados de sus justos derechos sobre las mercancías.

En el acto depredador contra los judíos de la barca siciliana, d'Àries fundamentó esos justos derechos en un argumento jurídico cuya legitimidad era indudable, desde su perspectiva y la de sus seguidores, mientras los saqueadores confiaran en su validez: amparándose en la condición religiosa de sus propietarios y obviando el vasallaje compartido por asaltantes y asaltados, redu-

8 La carga final embarcada por Francesc d'Àries en el Sankt Christophorus fue de 200 toneles, pero no se conocen los productos contenidos en ellos. Tan sólo el destino final (importante centro del tintado del cuero) y la riqueza natural de algunas de las escalas del trayecto (como las salinas próximas al Cap de Cerver, en el extremo sur de la corona de Aragón) hacen pensar en un comercio de materias primas textiles y de sal. 
jeron las mercancías judías a la categoría «de buena guerra». Que la compañía del Sankt Christophorus era consciente de la ilegalidad de la acción lo demuestra el intento por eliminar cualquier prueba del crimen, y prioritariamente el cartulario del escribano del San Giuliano, que a instancia de d'Àries fue robado por el escribano de la nave alemana y -no en vano- mozo del mercader valenciano.

Sin embargo, la magnitud del botín exigía la complicidad no sólo del fámulo de d'Àries y del resto de sus subalternos, sino también de varios hombres de Johannes Coleth, que en efecto participaron en el saqueo. Y, aunque pueda resultar ilógica la decisión de unos marineros de arriesgar su seguridad, actuar contra las autoridades de un país musulmán - garante mediante salvoconducto de las mercancías apresadas - y colaborar en una operación depredadora de la que no obtendrían ningún beneficio directo, una última cláusula del fletamento desvela la comprometida situación en la que aquéllos se vieron envueltos.

Cuando en febrero de 1413, mediante instrumento público, se firmó el mencionado contrato en Valencia, Johannes Coleth había dado a flete su embarcación al través o «d'alt a baix». Esta modalidad de alquiler naval se había difundido en la práctica contractual catalano-aragonesa de fletamentos de embarcaciones durante la segunda mitad del siglo XIV como consecuencia de las transformaciones del comercio marítimo mediterráneo operadas desde finales del siglo XIII y a lo largo de aquella centuria y revirtió en un mayor interés de los hombres de negocios mediterráneos por mercancías de reducido valor añadido y, por ello, en la necesidad de transportar mercancías heterogéneas y en grandes cantidades que exigían una amplia disponibilidad de espacio en las bodegas de las naves. El fletamento al través o «d'alt a baix» se caracterizaba, así, porque el alquiler afectaba a totalidad de la nave, dividida en unidades de carga o «quintarades» (García Sanz, 1978: 245-248). Sin embargo, el mercader valenciano no sólo se procuró todo el espacio de la nave susceptible - por derecho marítimo - de alquilar a un fletador para el transporte de mercancías, sino que además se reservó la propiedad de todas las «quintarades» de los marineros - y en espacio de carga similar al de ellos - que debería pertenecerles según la «costumbre de España».

Amén de la incidencia de la «costumbre de España» en el fletamento firmado entre d'Àries y Coleth, y en general en el ámbito marítimo, ${ }^{9}$ en función

9 La aparición de la «costumbre de España» como fuente del derecho naval de la corona aragonesa fue advertida hace ya casi medio siglo por A. García Sanz, quien lo interpretó como un trasvase de normas 
de este mismo derecho consuetudinario todas las eventuales ganancias derivadas del desarrollo de una empresa marítima mercantil debían repartirse en tres partes iguales: una correspondería al mercader que había fletado la embarcación, otra a la nave y una tercera a la compañía. ${ }^{10}$ Asimismo, el Llibre de Consolat de Mar establece que un número determinado de «quintarades», debía repartirse entre los marineros que habían trabajado durante el viaje en tanto que porcentaje sobre el producto del flete. ${ }^{11}$

Abarcando todo el espacio de carga del Sankt Christophorus, d'Àries podía obtener mayor beneficio del fletamento. Así, aunque los marineros hubieran teniendo derecho a una parte del botín, éste no podría haber sido embarcado en el Sankt Christophorus por quedar todas las «quintarades» de la nave en propiedad del mercader de Valencia; y, contrariamente, aunque ésta hubiera tenido espacio para cargar la parte del botín de aquéllos, no podrían haberlo hecho por no tener reconocido en el contrato de fletamento un derecho de apropiación parcial del mismo. De esta forma, d'Àries se encontraba ante una situación muy favorable para negociar con los marineros dispuestos a colaborar en el asalto, mediante la cesión de algunas «quintarades», haciéndose con una porción del botín mayor de lo que por derecho o costumbre le pertenecía.

En efecto, el acuerdo alcanzado entre d'Àries y algunos hombres de Coleth no satisfizo a toda la compañía, especialmente a su propio agente mercantil en Túnez, Nicolau Julià. La intransigencia del factor de d'Àries respecto al acto depredador cometido contra los judíos sicilianos suponía un serio problema para su éxito y precipitó episodios de violencia verbal que traspasaron el límite de la distensión y provocaron que aquél temiera por su seguridad. Al fin y

jurídicas de un régimen institucional singular relacionado con la penetración de la tradición marítima atlántica en el Mediterráneo (García Sanz, 1969: 227-231). La composición multicultural de la compañía del Sankt Christophorus, cuyos integrantes procedían en su mayor parte de espacios políticos atlánticos apunta en esta misma dirección y abre una sugestiva vía de estudio sobre la confrontación de tradiciones jurídicas marítimas distintas en el mare nostrum como expresión de la incidencia de las fronteras a bordo de una misma embarcación o, lo que es lo mismo, como una manifestación más de la frontera marítima en el Mediterráneo bajomedieval (Salicrú, 2000: 695).

10 García Sanz (1969: 275 y 274-277) recoge uno de los pocos contratos de fletamento firmado según «costumbre de España» que se conocen: «de omnibus aventuris quas dominus Deus dederit ipsi navi, tam de intrata quam de exitu, fiant tres partes equales : una quarum sit dicte navis, altera vero de la companya, et tercia vestri» (Biblioteca de la Sociedad Castellonense de Cultura, Manuscritos, Formulario del notario de Valencia Bertomeu Català, f. 104 y ss. 1402).

11 «Mercader qui noliejara nau o leny a quintalades, ço és a saber, que lo mercader deia dar quantitat de quintalades a la nau o al leny, lo senyor de la nau o del leny sia tengut de levar més lo quart de les quintalades» (Llibre de Consolat de Mar, c. 83). 
al cabo, la violencia era un mecanismo que la tensión provocada por la facticidad del delito hacía surgir como mecanismo de autoprotección, en general, y de salvaguardia de los intereses personales, en particular: cuando, el 8 de junio de 1413, el Sankt Christophorus partió del puerto de Túnez dispuesto a emprender el viaje de regreso a Valencia, Nicolau Julià no había podido cargar en la embarcación todos los cueros que había fletado a su socio d'Àries para llevar a la capital valenciana a causa del espacio ocupado en las bodegas por las mercancías judías, debiendo en consecuencia dejar un millar de aquellas pieles en la capital tunecina. Así que, consciente de que una actuación en contra de lo establecido por las autoridades de Ifriqiya podría comportar la retención o toma en prenda de las mismas, Julià empezó a mostrarse nervioso, profiriendo gritos y vilipendios a los miembros de la compañía que habían participado en los hechos. La reacción de éstos fue contundente: recurrieron a la extorsión y, amenazando con darle mal viaje o arrojarlo al mar, consiguieron su silencio condicional hasta Valencia.

Pero d'Àries debía aún resolver otro problema antes de llegar a Valencia, pues, aunque la nave no se había desplazado a Túnez en modo pirático, los judíos asaltados eran vasallos del rey de la Corona de Aragón y gozaban de su protección; de manera que los beneficios eventuales del viaje se habían conseguido malo modo.

Unos bienes ilegítimos como los embarcados en la nave alemana no podrían haberse descargado y comercializado en la capital valenciana sin pasar antes por la corte del baile general, donde además d'Àries habría debido declarar el botín y renunciar a una parte del mismo; así que, de acuerdo al itinerario de regreso a Valencia establecido en el contrato de fletamento, descargó en Málaga las mercancías de los judíos de Sicilia y durante ocho días las distribuyó allí, en Almería y en Granada. No es baladí la elección de esta escala en la travesía de vuelta que hizo incluir d'Àries en el fletamento. Participando de la penetración del grupo mercantil cristiano de Valencia en el reino de Granada durante la primera mitad del siglo XV, Francesc d'Àries comenzaba por el año en que ocurrió el episodio descrito a orientar sus intereses mercantiles hacia la costa granadina, hasta el punto de establecer allí centros de operación desde los que dirigía sus inversiones durante intervalos de tiempo variables. Así, si en 1412 participaba ya en el comercio con Granada avalando una galeota que recorría el trayecto Almería-Málaga desde Valencia (López Pérez, 1995: 200; Salicrú, 2007: 224), en 1415 se había afincado en Málaga y mantenía estrechos contactos comerciales con la ciudad de Granada, estableciendo 
para ello una red mercantil en la que agentes musulmanes actuaban de intermediarios de sus negocios granadinos. ${ }^{12}$ Sus relaciones con la sociedad granadina le acercó incluso a la élite dirigente nazarí, hasta el punto de mediar ante ellos por los reyes aragoneses y de conseguir del sultán el monopolio de importación y venta de la sal en el reino de Granada. ${ }^{13}$ Su vinculación con los principales centros económicos granadinos fue permanente a lo largo de la vida de este mercader valenciano, como demuestra el que en 1452, en un momento ya de avanzada edad, entregue en ofrenda una arroba de velas de sebo a la iglesia de los mercaderes cristianos de Almería, donde poseía también una casa propia (Hinojosa, 1978: 120; Hinojosa, 1987: 100; Salicrú, 1999b: 127; Salicrú, 2007: 216).

\section{Manifestaciones de la frontera marítima}

El episodio descrito en los párrafos anteriores demuestra que, en la medida en que el Mediterráneo no estaba incorporado a ningún espacio político de los poderes marítimos, cualquier actuación de uno de ellos o, incluso, de un súbdito a título individual podía tener vía libre; y no sólo frente a otro poder político o vasallo, sino que muchas veces la frontera se situaba en el interior de las compañías marítimas, propiciando fenómenos de interculturalidad, solidaridad y violencia que se intensifican cuando hay minorías étnico-religiosas por medio (Salicrú, 2000: 693-694). El mar quedaba por encima de las realidades políticas de la frontera terrestre, porque las traspasaba en función de la voluntad humana y de la lógica del beneficio económico. Así entendida, la concepción de la frontera marítima no depende tanto de la nacionalidad, o la procedencia de las personas o las mercancías, como de las iniciativas individuales.

Francesc d'Àries conocía muy bien el desconcierto que generaba el mar en tanto que frontera marítima, de modo que cuando tuvo conocimiento de la obediencia de los judíos del San Giuliano al rey de Aragón, un simple mecanismo de despersonalización de «el otro» fue suficiente para perpetrar sus actos. Alegando el desconocimiento del vasallaje compartido por asaltantes y

12 En 1415 envió a la capital nazarí 500 doblas por medio de un musulmán granadino. Archivo de la Corona de Aragón (ACA), Cancillería (C), registro (reg.) 2391, f. 8r-v. 1415, julio, 28. Valencia (Hinojosa, 1978: 106 y n. 36; Salicrú, 2007: 224).

13 ACA, C., reg., 2788, f. 105v. 1426, agosto, 22. Valencia (Garí y Salicrú, 1996: doc. 3; Salicrú, 1998 : 205-206; Salicrú, 1999a: doc. 134; Salicrú, 1999b: 128; Rodríguez Molina, 1999: 321; Salicrú, 2007: 293). 
asaltados, sus acciones podían ser legítimas sobre unas mercancías tomadas en virtud de la condición de sus propietarios.

$\mathrm{El}$ argumento «de buena guerra» se presenta así como una particular institución jurídica a merced de la confusión en el mar y aplicable en función de las ventajas y desventajas que una eventual capción pudiera implicar en relación a los objetivos impuestos, una decisión que debe tomarse, además, de forma inmediata, en condiciones extremas y bajo estados de fuerte excitación, por lo que no cabe esperar que se base en una evaluación correcta (Torró, 2008: 442). Cuando la negativa de algunos marineros truncó los planes de d'Àries, el mercader valenciano se vio obligado a negociar con ellos. Ello explica la participación de algunos miembros de la compañía en la capción de un botín por lo demás ilegítimo y, sobre todo, permite comprender la rápida liquidación de las mercancías apresadas en Málaga y Granada y, con ello, la eliminación de toda prueba, además de la elusión del pago ante la autoridad valenciana.

De todo ello se desprende la utilidad de la fuente utilizada para profundizar en el conocimiento de la frontera marítima. En el medievalismo hispánico, en general, y en el catalano-aragonés en particular, son numerosos los trabajos sobre la frontera terrestre; no tanto los centrados en la otra frontera, por lo demás estudiada a partir de registros de Cancillería, ricos en datos sobre episodios de violencia intercultural y/o internacional, reclamaciones por actos de piratería y confesiones de cautivos. Pero, junto a los legajos cancillerescos, también los libros de bailía general contienen una valiosa información sobre los negocios marítimos, los delitos cometidos en el mar, las autorizaciones para armar barcos y practicar el comercio exterior, etc. Asimismo, los protocolos notariales y otros fondos conservados en el Archivo Municipal de Valencia - en concreto las lletres misives - presentan amplias posibilidades de estudio y no constituyen vías agotadas de investigación.

En rigor, el recurso a una u otra fuente está condicionado al tipo de estudio a realizar y, por ello, a las múltiples expresiones de la frontera marítima. $\mathrm{Si}$, ante todo, la frontera marítima puede manifestarse en tanto que frontera natural y en tanto que frontera humana - dimensión, esta última, que no puede ignorarse, en la medida en que condicionaba no sólo la navegación, sino también la vida marítima y la serie de actividades que llenaba de significado su existencia-, parece lógico que la investigación pionera en los estudios fronterizos sobre el Mediterráneo bajomedieval centre su atención en ambas dimensiones, sin subordinar una a la otra. 
El ejemplo de Abrafim Genim, de principios de 1413, es un reflejo evidente de la realidad del Mediterráneo bajomedieval. Si, tal y como la ha definido Roser Salicrú la frontera marítima venía determinada, o se desplazaba, con cada nave, e incluso - a juzgar por la composición de las compañías mercantiles - en el interior de la misma, el contacto entre dos embarcaciones sin embargo podía situar la frontera en un límite transmutado que no siempre corresponde con una frontera terrestre. El mar, pues, a lo largo del periodo bajomedieval quedó por encima de las realidades políticas de la frontera terrestre, porque las traspasaba en función de la voluntad humana y de la lógica del beneficio económico. Así entendida, la concepción de la frontera marítima no dependía tanto de la nacionalidad, o la procedencia de las personas o las mercancías, como de las iniciativas individuales.

Sólo así se comprende que las comunidades musulmanes y judías, frente y junto al grupo social mercantil cristiano, alcanzaran un volumen comercial notable en el tráfico norteafricano, diseñando estrategias y mecanismos de integración y negocio y, también, conociendo los problemas de mantenimiento, supervivencia y éxito de inversiones en este tráfico comercial, como los propios de la frontera marítima mediterránea - corso, piratería y/o formas de violencia-, la exclusión de redes económicas, el favoritismo fiscal y las detenciones e impedimentos puntuales de sus actividades.

El desarrollo de unas formas de negocio condujo a construir específicas y notables empresas musulmanas y judías, como la reseñada, unos sistemas de relación con las colonias cristianas - junto con sus correligionarios en el Magreb y el sultanato nazarí-, no exentas de intermitencias y apoyos específicos en los que, junto a las cotidianidades suscitadas en la frontera marítima, funcionaban también los lazos de solidaridad y negocio con mercaderes e instituciones cristianas.

\section{Referencias bibliográficas}

AlarCón, Maximiliano A.; GARCÍA, Ramón (1940), Los documentos árabes diplomáticos del Archivo de la Corona de Aragón. Madrid-Granada, Escuelas de Estudios Árabes de Madrid y Granada.

ARIÉ, Rachel (1990), L'Espagne musulmane au temps des Nasrides: 1232-1492. París, De Boccard, 1990.

BARCEló, Carmen; LABARTA, Ana María (1990), «Los cuadernos árabes del reino de Granada: bibliografía y perspectivas», Cuadernos de la Alhambra, 26: 113-119. 
BARRIO, Juan Antonio (2011-2013), «El concepto de frontera en la Edad Media. La frontera meridional del reino de Valencia. Siglos XIII-XV», Sharq Al-Andalus, 20: 41-65.

Belenguer, Ernest (2015), Vida y reinado de Pedro IV el Ceremonioso (1319-1387). Lleida, Milenio.

Borghese, Gian Luca (2013), «The City of Foreigners: Palermo and the Mediterranean From the $11^{\text {th }}$ to the $15^{\text {th }}$ Century». En A. Nef (ed.), A Companion to Medieval Palerm: The History of a Mediterranean City From 600 to 1500. Leiden-Boston, Brill: $325-348$.

BRAUDEL, Fernand (1949), La Méditerranée et le monde méditerranéen à l'époque de Philippe II. París, Armand Colin.

CABEzUELO, José Vicente (1997-1998) «El negocio del rapto en la frontera de Orihuela a principios del siglo XIV», Miscelánea Medieval Murciana, XXI-XXII: 43-58.

CABezuelo, José Vicente; Soler J. Leonardo (2006), «'Por aquella tierra que esta en medio': violencia y negocio en la frontera meridional valenciana durante el primer tercio del siglo XIV». En F. Toro y J. Rodríguez (eds.), VI Estudios de Frontera : población y poblamiento : homenaje a Don Manuel González Jiménez. Jaén, Diputacion Provincial de Jaén: 133-150.

Claramunt, Salvador (2002-2003), «La política matrimonial de la Casa condal de Barcelona y Aragón desde 1213 hasta Fernando el Católico», Acta Historica et Archaeologica mediaevalia, 23-2: 195-235.

DíAZ, Andrés (1986), «Notas sobre los primeros tiempos de la atención valenciana a la redención de cautivos cristianos (1323-1399)», Estudis Castellonencs, 3: 337 353.

DíAZ, Andrés (1988a), «La paradoja de la emigración mora en Valencia durante el siglo XV. Expatriación musulmana en época de Honorat Mercader (1467-1481)», Cuadernos de Estudios Medievales y Ciencias y Técnicas Historiográficas, 16: 37-58.

DíAZ, Andrés (1988b), Problemas marítimos de Valencia a fines de la Edad Media: el corso, la piratería y el cautiverio en su incidencia sobre la dinámica económica: 1400-1480. Valencia, Universidad de Valencia.

DíAZ, Andrés (1990), «L'estudi de la pirateria a través dels avisaments costaners. Replegament cristià i setge islàmic a la València de la transició a la Modernitat: 14801520», Anuario de Estudios Medievales, 20: 275-295.

DíAZ, Andrés (1993), Los orígenes de la piratería islámica en Valencia. La ofensiva musulmana trecentista y la reacción cristiana. Barcelona, C.S.I.C.

DURAN, Daniel (2005), «De l'autonomia a la integració: la participación sicilianaa en el comerç oriental als segles XIV i XV». En M. T. Ferrer, J. Mutgé y M. Sánchez (eds.), La Corona Catalanoaragonesa i el seu entorn mediterrani a la Baixa Edat Mitjana. Barcelona, CSIC: 65-99.

FERRER, Maria Teresa (1987), La frontera amb l'Islam en el segle XIV: Cristians $i$ sarraïns al País Valencià. Barcelona, CSIC. 
FLORES, Manuel (1998), «La concepción del mar como frontera en los textos jurídicos del siglo XIII en las Coronas de Castilla y Aragón». En F. Toro y J. Rodríguez (eds.), II Estudios de Frontera: Actividad y vida en la frontera. Congreso celebrado en Alcalá la Real los días 19 al 22 de noviembre de 1997. Jaén, Diputación Provincial de Jaén: 245-255.

FLORES, Manuel (2000), «La interrelación de las fronteras terrestre y marítima en el periodo de la Reconquista». En F. Toro y J. Rodríguez (eds.), III Estudios de Frontera: Convivencia, defensa y comunicación en la frontera. Congreso celebrado en Alcalá la Real del 18 al 20 de noviembre de 1999. Jaén, Diputación Provincial de Jaén: 253-268.

GÁMIR, Alfonso (1960), «Las fortificaciones costeras del reino de Granada al Occidente de la ciudad de Málaga hasta el campo de Gibraltar», Miscelánea de Estudios Árabes y Hebraicos, IX-1: pp. 135-156.

GARCÍA, Arcadio (1969), «Estudios sobre los orígenes del Derecho Marítimo hispano-mediterráneo», Anuario de Historia del Derecho español, 39: 213-316.

GARCÍA, Arcadio (1978) «Fletamentos catalanes medievales», Historia, Instituciones, Documentos, 5: 235-256.

GARÍ, Blanca y SALICRÚ, Roser (1996), «Las ciudades del triángulo: Granada, Málaga, Almería, y el comercio mediterráneo de la Edad Media». En B. Garí y D. Abulafía (coords.), En las costas del Mediterráneo occidental: Las ciudades de la Península Ibérica y del reino de Mallorca y el comercio mediterráneo en la Edad Media. Barcelona, Omega: 171-211.

HinOJOSA, José (1975), «Piratas y corsarios en la Valencia de principios del siglo XV (1400-1409)», Cuadernos de Historia. Anexo de Hispania, 5, Madrid: 93-116

HinOJOSA, José (1978) «Las relaciones entre los reinos de Valencia y Granada durante la primera mitad del siglo XV». En Estudios de Historia de Valencia. Valencia, Universitat de València: 91-160.

HinOJOSA, José (1985), «Mudéjares granadinos en el reino de Valencia a fines del siglo XV (1484-1492». En III Coloquio de Historia Medieval Andaluza. Jaén: 120-130.

HiNOJOSA, José (1987), «Las relaciones entre Valencia y Granada durante el siglo XV: balance de una investigación». En Estudios sobre Málaga y el Reino de Granada en el $V$ Centenario de la Conquista. Málaga, Diputación Provincial de Málaga: 83-111.

HinojosA, José (1988), «Cristianos, mudéjares y granadinos en la Gobernación de Orihuela». En IV Coloquio de Historia Medieval de Andalucía. Almería: 323-342

HinOJOSA, José (1989), «Armamento de naves y comercio con el reino de Granada a principios del siglo XV». En V Coloquio de Historia Medieval de Andalucía. Córdoba, 643- 658

HinOJOSA, José (1990), «La piratería y el corso en las costas alicantinas durante la Baja Edad Media». En VIII Jornades d'Estudis Històrics Locals. El comerç alternatiu, Corsarisme i contraban (ss. XV-XVIII). Palma de Mallorca: 41- 54. 
HinojosA, José (2006-2008), «Los judíos en el reino de Valencia. Testigos de una historia secular», Anales de la Universidad de Alicante. Historia Medieval, 15 (El legado histórico de los judíos de la Corona de Aragón): 7-45.

HinojosA, José (2008), «Los Judíos en la Corona de Aragón. La recuperación de la memoria histórica en torno a una minoría». En M. F. Lopes de Barros y J. Hinojosa (eds.), Minorias étnico-religiosas na Península Ibérica. Periodos medieval e moderno. Évora-Alicante, Colibri: 93-142.

LÓPEZ DE COCA, José Enrique (1978), «Esclavos, alfaqueques y mercaderes en la frontera del Mar de Alborán (1490-1516)», Hispania: Revista española de historia, 38/139: 275-300;

LÓPEZ DE COCA, José Enrique (1982), «Los mudéjares valencianos y el reino nazarí de Granada. Propuestas para una investigación», En la España medieval. Homenaje a Salvador de Moxó, 1 .

LÓPEZ DE COCA, José Enrique (1989), «Institutions on the Castilian-Granadian frontier: 1369-1482». En R. Bartlett y A. Mackay (eds.), Medieval Frontier Societies. Oxford, Oxford University Press: 135-141.

LÓPEZ DE COCA, José Enrique (1997), «Consideraciones sobre la frontera marítima». En P. segura (ed.), Actas del Congreso 'La frontera oriental nazarí como sujeto histórico (s. XIII-XVI)', Lorca-Vera, 22 a 24 de noviembre de 1994. Almería, Instituto de Estudios Almerienses: 395-408.

LÓPEZ DE COCA, José Enrique (1999), «Institutions on the Castilian-Granadian frontier: 1369-1482». ER. Bartlett y A. Macaky (eds.), Medieval Frontier Societies. Oxford, Clarendon: 127-150.

LóPEZ, María Dolores (1995), La Corona de Aragón y el Magreb en el siglo XV (1331-1410). Barcelona, CSIC.

REYES, José Luis; RUBIO, Matilde (1987), «Estudio arqueológico de las Torres de Costa en la provincia de Granada». En Arqueología Medieval Española, II Congreso, Madrid 19-24 enero 1987. Madri, Comunidad de Madrid, Asociación Española de Arqueología Medieval: t. II, pp. 239-249.

RODRíGUEZ, José (1999), «Reflexiones sobre el reino de Granada», Revista de Història Medieval, 10: 312-327.

SAliCRÚ, Roser (1998), El sultanat de Granada i la Corona d'Aragó, 1410-1458. Barcelona, CSIC.

SALICRÚ, Roser (1999a), Documents per a la historia de Granada del regnat d'Alfons el Magnànim (1416-1458). Barcelona, CSIC.

SALICRÚ, Roser (1999b), «La Corona de Aragón y Génova en la Granada del siglo XV». En L'expansió catalana a la Mediterrània a la Baixa Edat Mitjana. Barcelona, CSIC (Anuario de Estudios Medievales. Annex 36): 121-144.

SALICRÚ, Roser (2000), «La frontera marítima en el Mediterráneo bajomedieval, en Convivencia, defensa y comunicación en la frontera». En F. Toro y J. Rodríguez (eds.), III Estudios de Frontera. Jaén, Diputación Provincial de Jaén: 681-709. 
SALICRÚ, Roser (2002), «Mudéjares y cristianos en el comercio con Berbería: quejas sobre favoritismo fiscal y acusaciones de colaboracionismo mudéjar una reacción cristiana a la defensiva». En VIII Simposio Internacional de Mudejarismo, Teruel, Instituto de Estudios Turolenses: 283-301.

SALICRÚ, Roser (2007), El sultanato nazarí de Granada, Génova y la Corona de Aragón en el siglo XV. Granada, Universidad de Granada.

SALICRÚ, Roser (2009), "Cartas árabes’ en romance conservadas en el Archivo de la Corona de Aragón». En F. Toro y J. Rodríguez (eds.), VII Estudios de Frontera: Islam y cristiandad, siglos XII-XVI. Homenaje a María Jesús Viguera Molins. Congreso celebrado en Alcalá la Real en noviembre de 2008. Jaén, Diputación de Jaén: 819-837.

SALICRÚ, Roser (2018), «Fronteras que no son frontera: musulmanes a norte y sur del estrecho de Gibraltar en el siglo XV», Vegueta, 18: 257-277.

SimonsoHn, Shlomo (2001), Between Scylla and Charybdis: The Jews in Sicily. Leiden-Boston, Brill.

Temboury, Juan (1975), Torres almenaras (costa occidental). Málaga, Diputación Provincial de Málaga.

TORRÓ, Josep (2008), «De bona guerra. El ambiguo estatuto del cautivo musulmán en los países de la Corona de Aragón (siglos XII-XIII)». En M. Fierro y F. García Fitz (eds.), El cuerpo derrotado. Cómo trataban musulmanes y cristianos a los enemigos vencidos (Península Ibérica, siglos VIII-XIII). Madrid, CSIC: 435-483.

UnALI, Anna (2007), Marineros, piratas y corsarios en la Baja Edad Media. Sevilla, Renacimiento (ed. or. en italiano: Bolonia, 1983).

VALÉRIAN, Dominique (2006), Bougie, port maghrébin, 1067-1510. Roma, École Française de Rome.

VALÉRIAN, Dominique (2016), «Les marchands latins dans les ports maghrébins: espaces d'échanges et de contacts», Revue de la Méditerranée, III/1: 33-44.

Zomeño, Amalia, (2001), «Repertorio documental arábigo-granadino: los documentos árabes de la Biblioteca de la Universidad de Granada», Qurtuba, 6: 275-296. 